\title{
Sedimentation control in the reservoirs by using an obstacle
}

\author{
MORTEZA MAROSI $^{1}$, MEHDI GHOMESHI $^{2}$ \\ and HAMED SARKARDEH ${ }^{3, *}$
}

\author{
${ }^{1}$ Hydraulic Structures Division, Water Research Institute, Tehran, Iran \\ ${ }^{2}$ Faculty of Water Sciences Engineering, Shahid Chamran University, Ahwaz, Iran \\ ${ }^{3}$ Department of Engineering, Hakim Sabzevari University, Sabzevar, Iran \\ e-mail: sarkardeh@hsu.ac.ir
}

MS received 11 March 2014; revised 13 August 2014; accepted 3 December 2014

\begin{abstract}
In the present experimental research, effect of different heights of obstacle on turbidity current, to control the sedimentation in a reservoir, was investigated. Experiments were carried out with horizontal and steep bed slopes and different flow conditions. To see the effect of obstacle on concentration of overflow turbidity current, some experiments were carried out without an obstacle. Results showed that concentration of the currents without obstacle reduced exponentially by distance from the entrance gate. More reduction of density and dilution of the currents were observed in the presence of an obstacle, especially with increasing the heights. Increasing height of obstacle also improved their trap efficiency. Moreover, it was concluded that effect of the presence of an obstacle was less intense in a steep bed slope of the reservoir than in a horizontal one.
\end{abstract}

Keywords. Reservoir sedimentation; turbidity current; obstacle; dilution; trap efficiency.

\section{Introduction}

River flows usually carry sediment particles within a wide range of sizes. When a river flows into a reservoir, the coarser particles deposit gradually and form a delta in the headwater area of the reservoir that extends further into the reservoir as deposition continues. In certain situations, the turbidity current, carrying fine particles, can move for several tens of kilometers (Fan \& Morris 1992). If the turbid inflow continuously flows into a reservoir, the turbidity current will sustain itself and arrive at the dam wall. When it reaches to the dam, the turbidity current can soar up and then a muddy lake will form. Schematic representation for a deposition delta, turbidity current region and a muddy lake is shown in figure 1.

In recent years, the sustainable use of the reservoirs is not guaranteed in the long term due to increase in sedimentation (Morris \& Fan 1998). Depending on the slope of the reservoir bed, density currents can reach high velocities up to $0.5-0.8 \mathrm{~m} / \mathrm{s}$ during floods (De Cesare et al 2001).

*For correspondence 


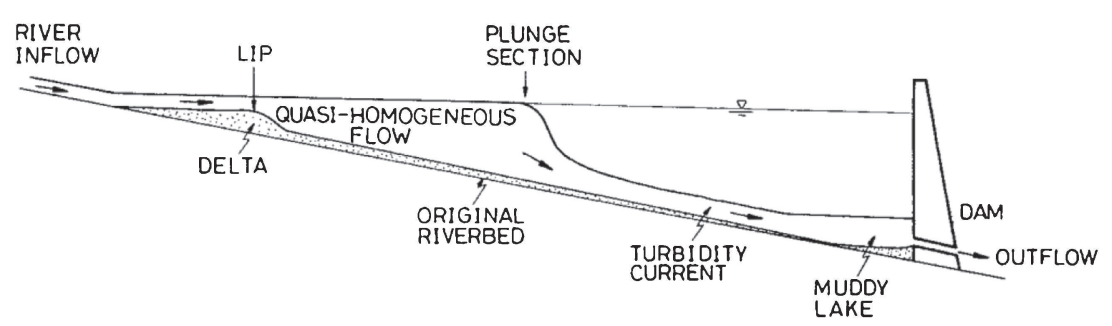

Figure 1. Turbidity current entering into a reservoir (Yu et al 2000).

If turbidity currents are able to be entirely stopped in a reservoir, or controlled in such a way to eliminate deposition of the sediments in critical locations like in front of the intakes or the bottom outlets, sustainability of the reservoir operation can be increased considerably. Control of the reservoir sedimentation due to turbidity currents has in principal purpose to stop, dilute, or divert the flow (Oehy \& Schleiss 2007). This can be done by an obstacle placed in the reservoir (figure 2). Submerged obstacles placed across the main flow in the deepest area of the reservoir can stop or divert the turbidity currents and force the fine sediments to settle into the reservoir where sediment depositions do not affect intake operation (Oehy \& Schleiss 2007).

Many researches have been performed on sedimentation in the reservoir with different solution approaches. Rottman et al (1985) solved analytically the current flow over a horizontal slope in the presence of an obstacle. They concluded that for complete block of the current flow, the obstacle height must be twice its current flow thickness. Alexander \& Morris (1994) investigated the effect of obstacle angle on turbidity current. In general, the results of their studies showed that the obstacle height depends totally on inflow characteristics. Lane-Serff et al (1995) studied the current flow over obstacle on a horizontal slope with fixed discharge values for varying current concentrations. They proposed some equations and diagrams in the form of dimensionless height against the ratio of current body thickness to the depth of water. Prinos (1999) conducted a research on the obstacle shape including half-circle and triangle shapes on a horizontal slope. He found that the obstacle shape has no significant effect on blockage of the current flow. Bursik \& Woods (2000) studied the effects of the obstacle on control of the current flow. Oehy \& Schleiss (2007) also studied the effects of obstacles on controlling turbidity currents at reservoirs. They studied the current flow over obstacle for a given height and two different slopes and finally concluded that presence of the obstacle works better for subcritical current flows. Oehy et al (2010) also studied the effects of inclined jet screen on turbidity current. The results indicated that in certain configurations, turbidity currents can be partially stopped by the jet screen.

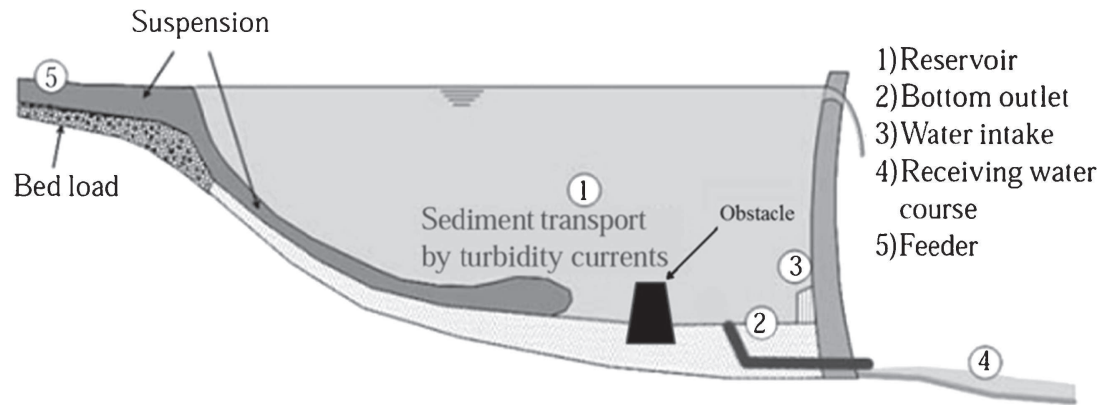

Figure 2. Control of turbidity current by embankment dam as an obstacle (Asghari et al 2010). 
According to the literature, no comprehensive research has been carried out on effects of obstacle on dilution of passed flow in different inflow conditions and obstacle heights in steady state conditions. Since the construction of an obstacle in dam reservoir is a new technique in reducing turbidity current impacts, more studies need to be conducted in this respect. In the present research a physical model has been used to study the effect of obstacle height on dilution of turbidity current with different concentrations and discharges and reservoir bed slopes.

\section{Dimensional analysis}

Amount of turbidity flow dilution or trap efficiency of obstacle is the main goal of these experiments. Initial variables used in the experiments with turbidity flow are as follows:

$$
f\left(V, h, h_{m}, v, C_{1}, C_{2}, g^{\prime}, S\right)=0,
$$

where $h$ is the current inflow thickness, $V$ is the turbidity flow velocity, $S$ is the reservoir bed slope, $h_{m}$ is the height of the obstacle, $g^{\prime}\left(=\left[\rho^{\prime}-\rho\right] \times g / \rho\right)$ is the reduced gravity of the current in which $\rho$ and $\rho^{\prime}$ are density of clear water and turbidity flow respectively, $v$ is kinematics viscosity of flow, $g$ is the acceleration due to gravity, $C_{1}$ and $C_{2}$ are concentrations of turbidity flow before and after of the obstacle. Using dimensional analysis with the aids of Buckingham $\pi$ theorem, the following equation can be found:

$$
F\left(T_{e}, F r_{d}, H_{m}, R e, S\right)=0
$$

where $T_{e}\left(=1-C_{2} / C_{1}\right)$ is amount of dilution or trap efficiency of obstacle, $R e$ is Reynolds Number of turbidity flow $(=V h / v), F r_{d}$ is densimetric Froude Number $\left(=V / \sqrt{ } g^{\prime} h\right)$ and $H_{m}\left(=h_{m} / h\right)$ is the dimensionless obstacle height. It should be noted that $T_{e}$ is a dependent parameter and then the equation can be rewritten as

$$
T_{e}=f\left(F r_{d}, H_{m}, R e, S\right)
$$

In all experiments, Reynolds Number was more than 500 and therefore according to Lane-Serff et al (1995), viscosity effect can be ignored:

$$
T_{e}=f\left(F r_{d}, H_{m}, S\right) .
$$

\section{Physical model and experimental set-up}

Experiments were performed in a flume with $8 \mathrm{~m}$ long, $0.35 \mathrm{~m}$ wide and $0.65 \mathrm{~m}$ high. A stilling rectangular reservoir and head tank were installed in the upper part of the flume. A sliding gate allowed releasing the turbidity current toward downstream part of the channel (figure 3 ).

After filling the flume with clear water, the turbidity flow was pumped up into the head tank and then the flow moved to the flume after passing from an electromagnetic flow meter with accuracy of $0.001 \mathrm{~L} / \mathrm{s}$. During preparation, the sliding gate was closed and the turbid flow returned through an orifice back into the mixture tank ensuring a uniform mixture in the stilling tank and an accurate regulation of the pump (figure 4).

The turbidity current was induced in the clear water by opening the sliding gate. The level of water in the flume was controlled by adding clear water and drainage valve installed end of flume (figure 4). A stilling basin was built at the end of the flume to reduce turbulence of adding 


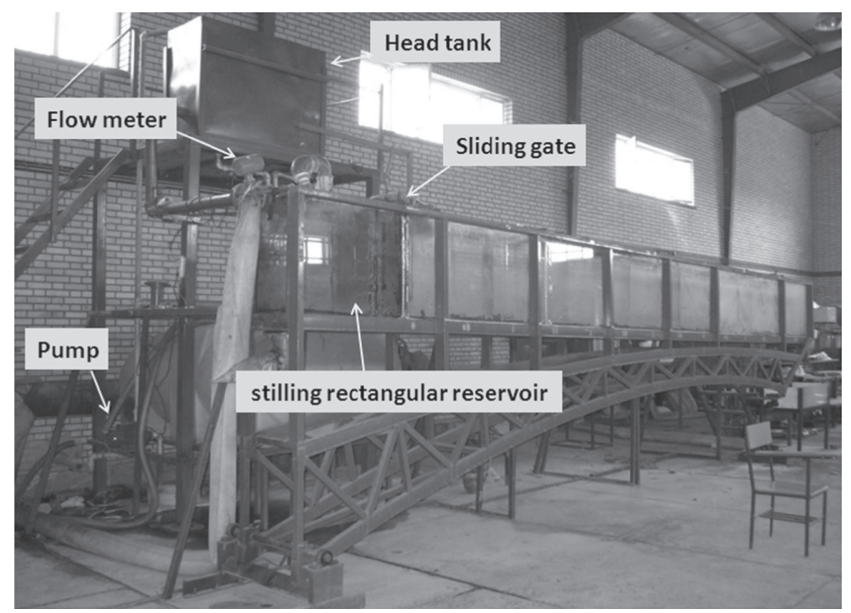

Figure 3. Experimental set-up of the present study.

water. The sediments were fine and non-cohesive particles with mean size of $D_{50}=15 \mu \mathrm{m}$ and $G_{s}=2.6$. Density of clear water and inflow turbidity currents were measured by a hydrometer with accuracy of $0.1 \mathrm{~kg} / \mathrm{m}^{3}$. The heights of the body of the turbidity currents $(h)$ were measured visually by installing a ruler in flume sidewalls. Samples from fluid in all experiments were taken before and after of the obstacle. After sampling, concentrations of turbidity current were measured. Whereas, obstacle geometry has no significant effect on the proportion of the flow continuing over it (Prinos 1999), obstacles used in this study were trapezoid and had $h_{1}=11$, $h_{2}=16$, and $h_{3}=21 \mathrm{~cm}$ heights, extending across the full width of the flume at a distance of $5 \mathrm{~m}$ far from inlet. All experiments were carried out on not movable bed. The inflow opening height was always equal to $3 \mathrm{~cm}$. Inflow discharges were $Q_{1}=0.5, Q_{2}=1$ and $Q_{3}=1.5 \mathrm{~L} / \mathrm{s}$ and bed slopes were $S_{1}=0$ and $S_{2}=3.85 \%$. Each experiment has been specified with $Q, S, h$, $N$. In all experiments, $N$ refers to the number of experiment.

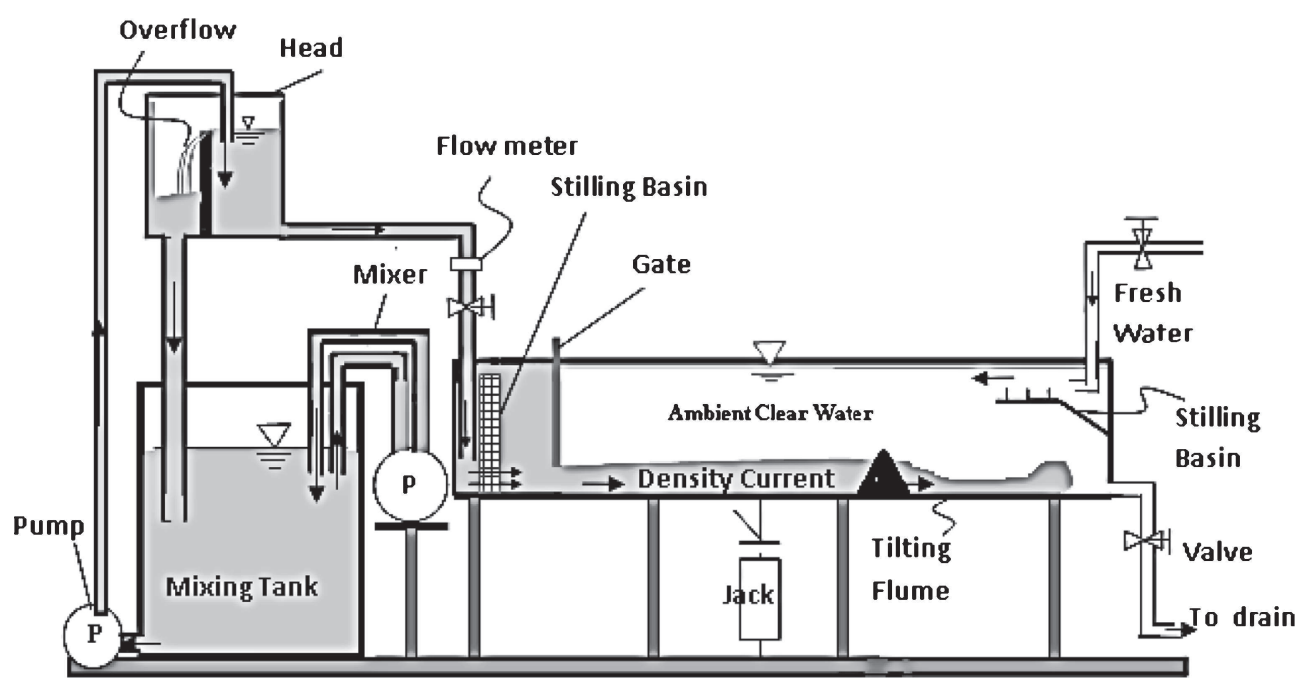

Figure 4. Schematic view of the constructed physical model. 

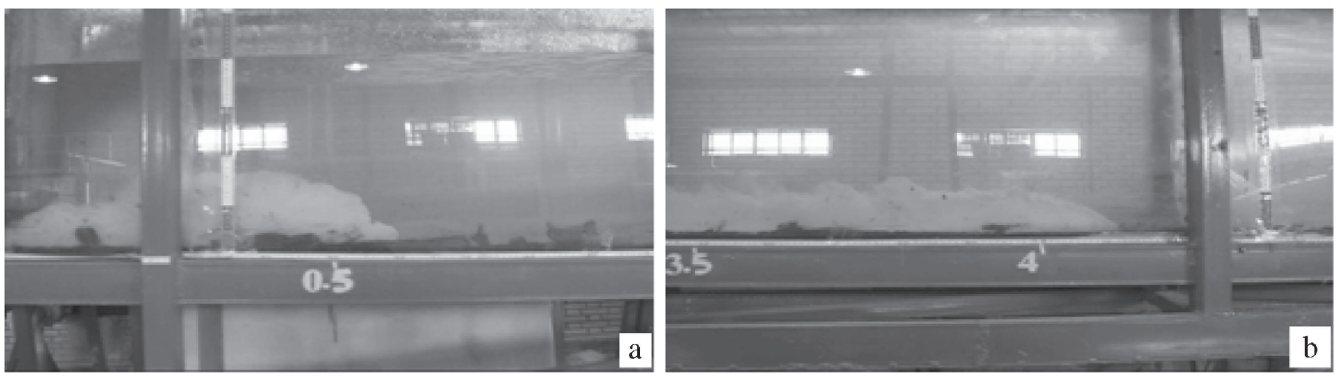

Figure 5. Head of turbidity current (Experiment $Q_{2} S_{2} N_{7}$ ).

\section{Results and discussions}

The results were presented in three parts. First part describes the flow behavior and formation of turbidity current, head velocity and effect of obstacle on turbidity current head velocity. The second part describes sedimentation of flow in general view without the presence of an obstacle in flume. Finally, the third part shows the effect of obstacle on trap efficiency of turbidity current.
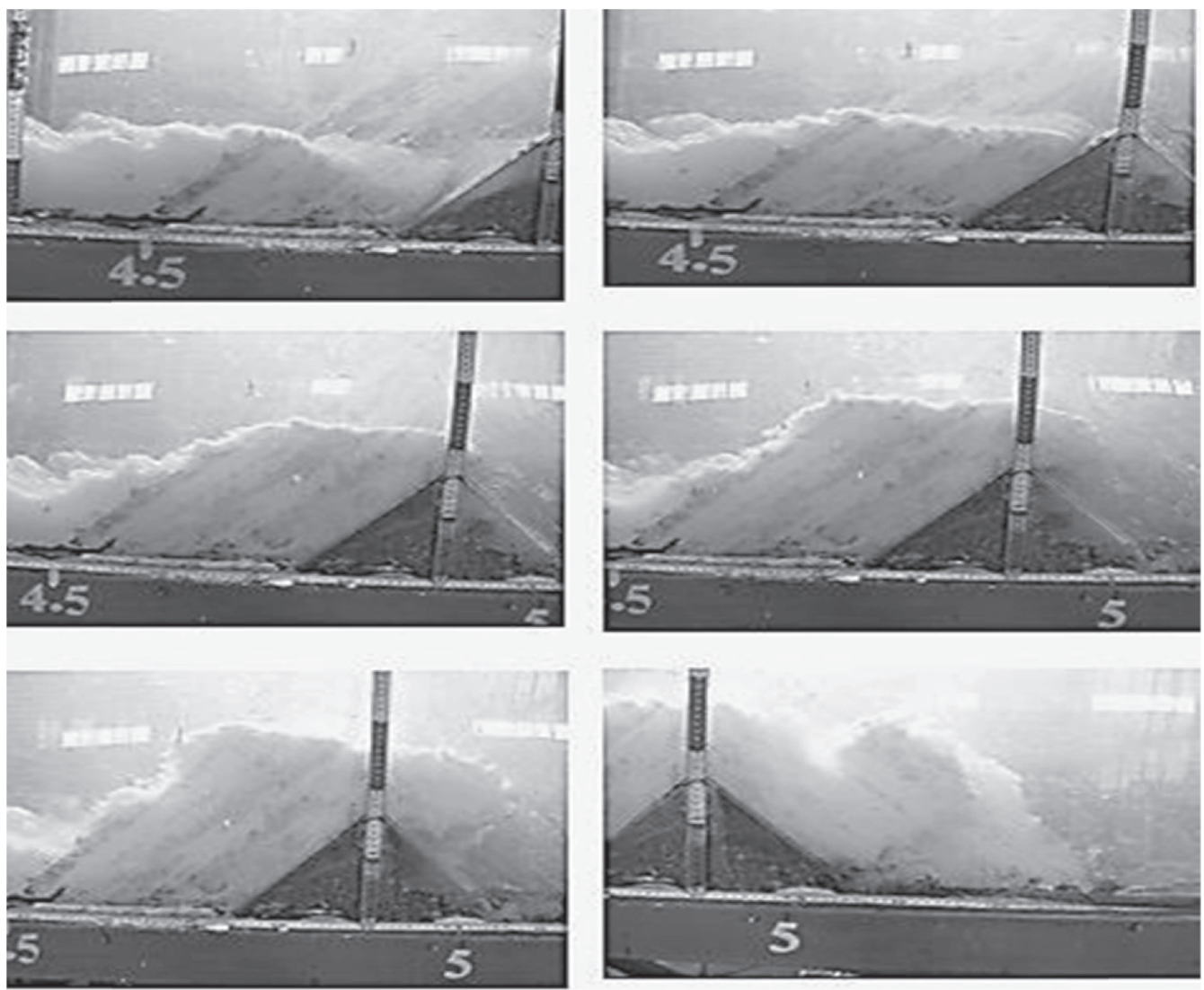

Figure 6. Photographic sequences of turbidity current over obstacle $\left(Q_{2} S_{2} h_{1} N_{1}\right)$. 


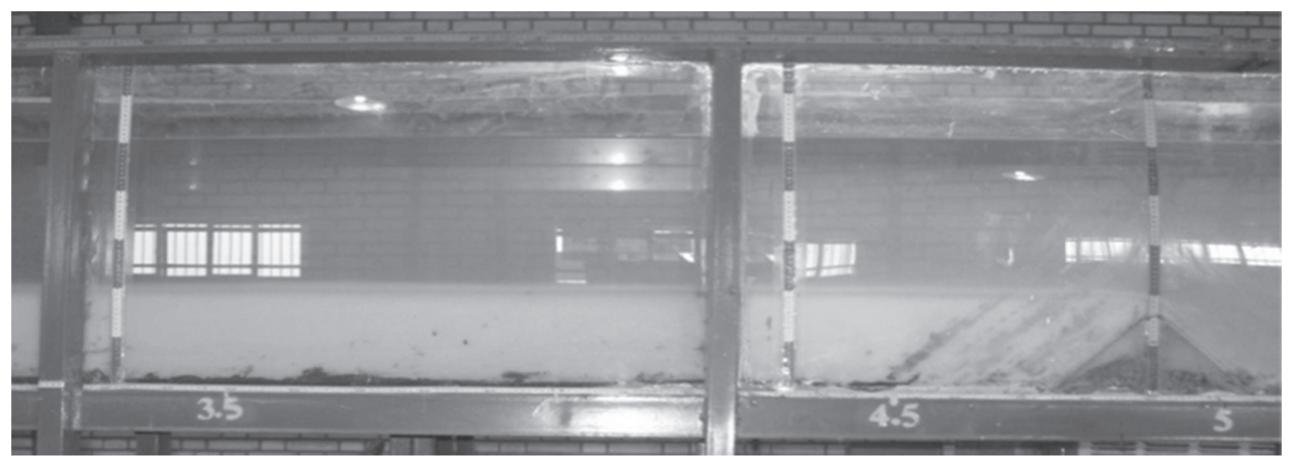

Figure 7. Steady flow upstream the obstacle $\left(Q_{2} S_{2} h_{1} N_{1}\right)$.

By pulling the gate up, because of density difference between clear water and turbid fluid; turbidity current forms and moves toward downstream. Due to the momentum, especially in case of high discharges, the head of turbidity current was initially high. But within the first meters from the entrance gate, this initial head formation rapidly adjusted to an equilibrium height (figure 5a) and continued to advance steadily within the flume followed by a body with smaller height (figure 5b). When the turbidity current reaches to an obstacle, climbs up and decelerates slightly and then its head passes over the obstacle (Oehy \& Schleiss 2007). In the present work, as can be seen in the photographic sequence of figure 6 , such trend was observed. It was also observed that the normal shape of the frontal region was re-established at some distance downstream of the obstacle. After passing the turbidity current away from the obstacle, a steady flow was observed upstream of the obstacle (figure 7). In some experiments, to show the effect of obstacle on head velocity of turbidity current, head velocities were measured by using a digital camera before and after of the obstacle. Results are shown in table 1 for zero slope condition. In this table, $U_{f u}$ is the front velocity of the turbidity current upstream of the obstacle and $U_{f d}$ is the velocity of outgoing continuing turbidity current downstream. Moreover, front velocities in all experiments were approximately constant over the measuring sections. It should be noted that regarding table 1 , the front velocities decreased downstream of the obstacle because of decreasing the buoyancy flux.

To have better understanding about turbidity current sedimentation, some experiments were performed without obstacle. The detailed description of the experimental parameters can be found in table 2. In this series of experiments, after turbidity current head reached to the end of flume, samples were taken from the body of the turbidity current in eight points along the flume.

Table 1. Head velocity (in all experiments, $\mathrm{S}=S_{1}$ ).

\begin{tabular}{lll}
\hline Experiment & $U_{f u}$ & $U_{f d}$ \\
\hline$Q_{1} H_{1}$ & 0.0374 & 0.0191 \\
$Q_{2} H_{1}$ & 0.053 & 0.035 \\
$Q_{3} H_{1}$ & 0.07 & 0.045 \\
$Q_{1} H_{2}$ & 0.051 & 0.021 \\
$Q_{2} H_{2}$ & 0.065 & 0.027 \\
$Q_{3} H_{2}$ & 0.075 & 0.0625 \\
$Q_{1} H_{3}$ & 0.05 & 0.031 \\
$Q_{2} H_{3}$ & 0.045 & 0.0419 \\
$Q_{3} H_{3}$ & 0.081 & 0.05 \\
\hline
\end{tabular}


Table 2. Experimental parameters of turbidity currents without the presence of obstacle.

\begin{tabular}{lclc}
\hline Experiment & $\Delta \rho\left(=\rho^{\prime}-\rho\right)\left(\mathrm{kg} / \mathrm{m}^{3}\right)$ & $\Delta \rho / \rho$ & $g^{\prime}\left(\mathrm{m} / \mathrm{s}^{2}\right)$ \\
\hline$Q_{1} S_{1} N_{1}$ & 12.5 & 0.01249 & 0.1226 \\
$Q_{1} S_{1} N_{2}$ & 8.7 & 0.00873 & 0.0856 \\
$Q_{2} S_{1} N_{3}$ & 9 & 0.00899 & 0.0882 \\
$Q_{3} S_{1} N_{4}$ & 10.5 & 0.0105 & 0.0015 \\
$Q_{1} S_{2} N_{5}$ & 8.5 & 0.0085 & 0.0834 \\
$Q_{2} S_{2} N_{6}$ & 6 & 0.006 & 0.0588 \\
$Q_{2} S_{2} N_{7}$ & 10.7 & 0.0107 & 0.105 \\
$Q_{3} S_{2} N_{8}$ & 10.5 & 0.0105 & 0.1029 \\
$Q_{2} S_{2} N_{9}$ & 8.2 & 0.00824 & 0.0809 \\
\hline
\end{tabular}
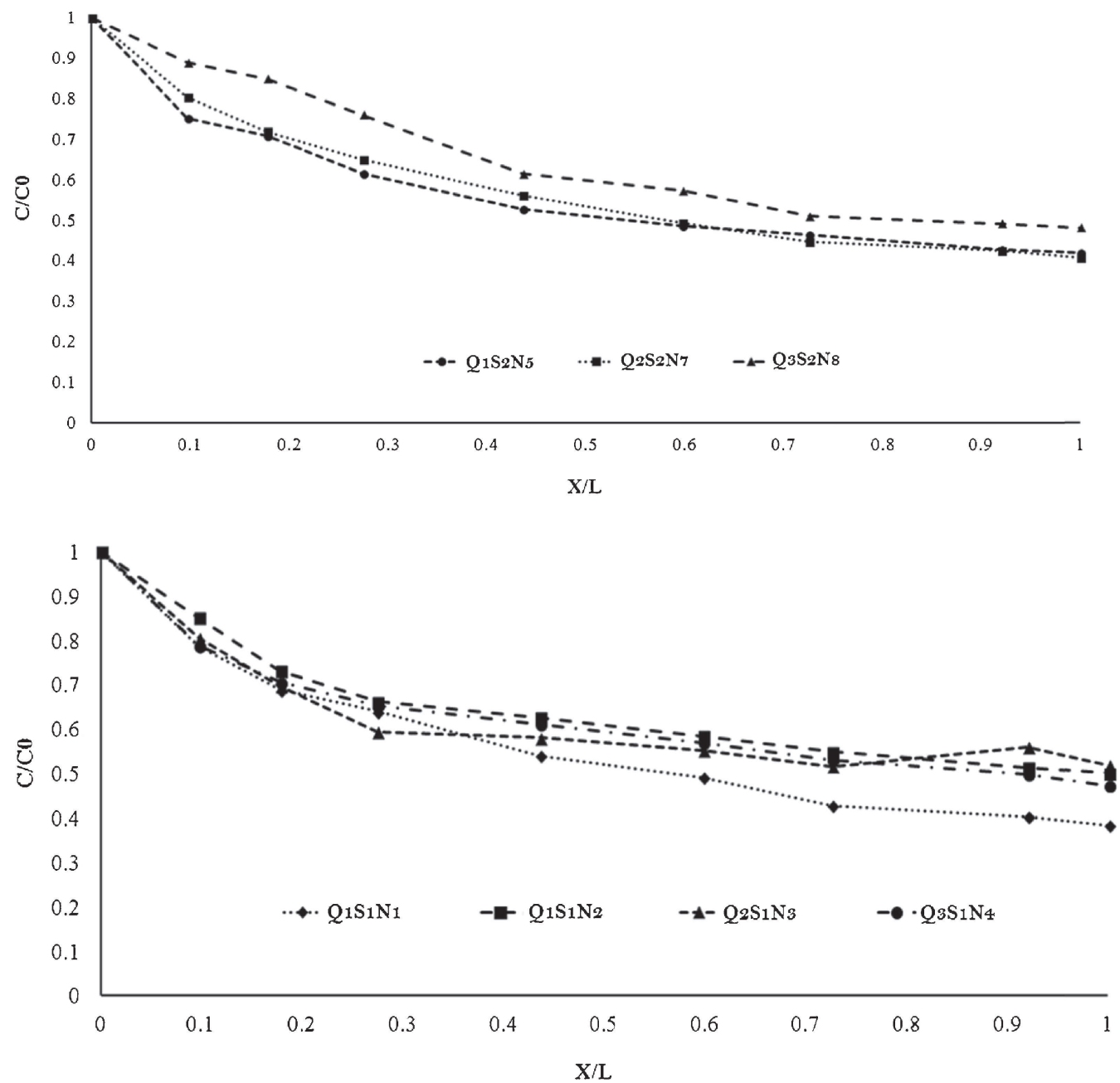

Figure 8. Reduction of turbidity current concentration without obstacle in different slopes. 
In figure 8 the relative concentration is plotted against relative distance in different situations. In this figure $X / L$ is dimensionless distance from entrance gate, $L$ is the total flume length, $X$ is distance from entrance gate, $C / C_{0}$ is dimensionless concentration parameter where $C_{0}$ is initial turbidity current concentration and $C$ is concentration in each point of the flume. From figure 8 , it is obvious that the concentration of turbidity was reduced along the flume in both slopes. Moreover, from this, it could be concluded that the amount changes of dilution are more intense in the spots right after the gate than the other places. Coarse sediment settling down immediately after gate is the reason of such steep slope in the curve at figure 8. However, fine sediments had enough time for settling down and therefore downstream of the curve in figure 8 has smoother slope. Also, horizontal bed had better performance in settling down of sediments in comparison with steeper one. In lower discharges, sedimentation is increased. In general, the process of sedimentation and also dilution of turbidity current is reduced exponentially along flume length and is agreed with result of Woods et al (1998). In the third series of experiments, an obstacle with different heights was installed in the model at a distance of $5 \mathrm{~m}$ after gate. Experimental parameters of turbidity current with obstacle are summarized in table 3 . In all experiments with different initial conditions and different obstacle heights and slopes, concentration of turbidity current was measured before and after of the obstacle. To show the effect of obstacle height, $H_{m}$ was plotted versus $T_{e}$ in figure 9 .

As can be seen in this figure, trap efficiency increases with increase in obstacle height. In horizental slope, the trap efficiency is about $10 \%$ larger than the trap efficiency of steep slope. In figure $10, F_{r d}$ is plotted versus $T_{e}$ to show the effect of inflow condition. As can b seen in this figure, increasing $F r_{d}$ will decrease the effect of obstacle in trap efficiency of turbidity current.

Table 3. Experimental parameters of turbidity current in the presence of obstacle.

\begin{tabular}{lcll}
\hline Experiment & $\Delta \rho\left(=\rho^{\prime}-\rho\right)\left(\mathrm{kg} / \mathrm{m}^{3}\right)$ & $\Delta \rho / \rho$ & $g^{\prime}\left(\mathrm{m}^{2} / \mathrm{s}\right)$ \\
\hline$Q_{1} S_{1} H_{1} N_{1}$ & 14 & 0.01399 & 0.1373 \\
$Q_{2} S_{1} H_{1} N_{2}$ & 8.5 & 0.00849 & 0.0833 \\
$Q_{3} S_{1} H_{1} N_{3}$ & 10.5 & 0.01051 & 0.1013 \\
$Q_{1} S_{2} H_{1} N_{4}$ & 6.5 & 0.00649 & 0.637 \\
$Q_{2} S_{2} H_{1} N_{5}$ & 10 & 0.01 & 0.981 \\
$Q_{3} S_{2} H_{1} N_{6}$ & 10.8 & 0.01079 & 0.1059 \\
$Q_{2} S_{2} H_{1} N_{7}$ & 6.5 & 0.00649 & 0.0637 \\
$Q_{2} S_{2} H_{1} N_{8}$ & 9.5 & 0.0095 & 0.0932 \\
$Q_{2} S_{2} H_{1} N_{9}$ & 12.5 & 0.01248 & 0.1225 \\
$Q_{1} S_{1} H_{2} N_{10}$ & 7.7 & 0.00774 & 0.0759 \\
$Q_{2} S_{1} H_{2} N_{11}$ & 11.7 & 0.01171 & 0.1149 \\
$Q_{3} S_{1} H_{2} N_{12}$ & 10.9 & 0.01093 & 0.1012 \\
$Q_{1} S_{2} H_{2} N_{13}$ & 13.2 & 0.01218 & 0.1293 \\
$Q_{2} S_{2} H_{2} N_{14}$ & 12.7 & 0.0127 & 0.1249 \\
$Q_{1} S_{2} H_{2} N_{15}$ & 10.7 & 0.0107 & 0.105 \\
$Q_{1} S_{1} H_{3} N_{16}$ & 13.2 & 0.01318 & 0.1293 \\
$Q_{2} S_{1} H_{3} N_{17}$ & 11.7 & 0.01169 & 0.1146 \\
$Q_{3} S_{1} H_{3} N_{18}$ & 15 & 0.0105 & 0.1471 \\
$Q_{1} S_{2} H_{3} N_{19}$ & 13.2 & 0.01315 & 0.1290 \\
$Q_{2} S_{2} H_{3} N_{20}$ & 11.7 & 0.01049 & 0.1029 \\
$Q_{3} S_{2} H_{3} N_{21}$ & 15 & 0.014 & 0.1373 \\
\hline
\end{tabular}




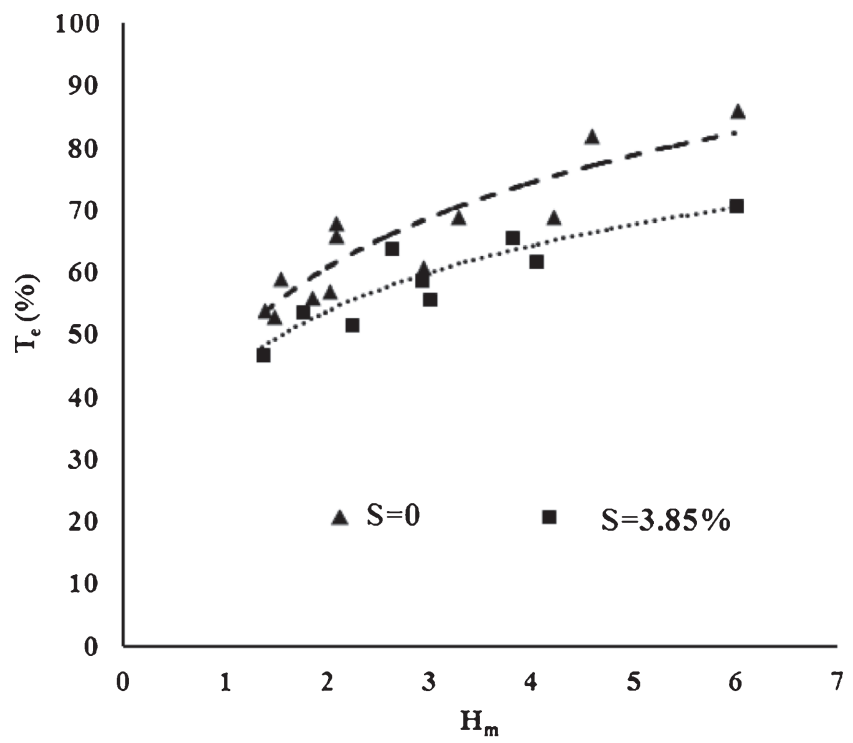

Figure 9. Effect of obstacle height on trap efficiency.

Equation 5 was derived from all experimental data and correlates trap efficiency to other effective parameters in this research work $\left(R^{2}=0.95\right)$.

$$
T_{e}=\left[0.25 H_{m}^{0.31}+0.36 F_{r d}^{-0.34}-2 S\right] \times 100 .
$$

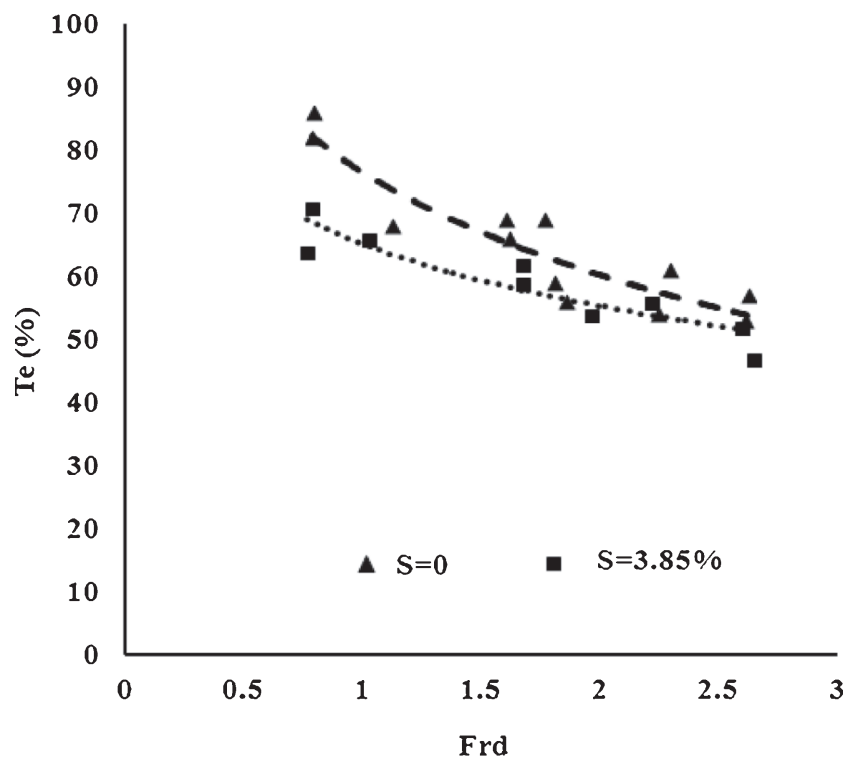

Figure 10. Effect of inflow condition on trap efficiency. 


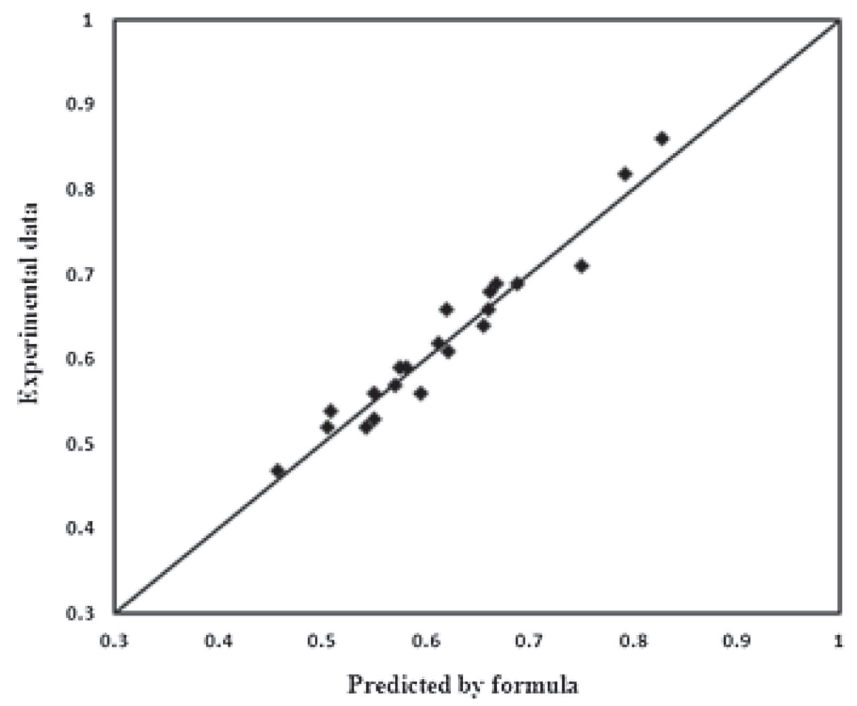

Figure 11. Predicted and measured trap efficiency.

To determine the accuracy of this equation, the estimated and measured trap efficiency is plotted in figure 11. As can be seen in this figure, the predicted data with Eq. 5 is very close to measured data.

\section{Conclusion}

Turbidity current is one of the challenging problems in the reservoir and dam operation. Installing obstacle is a prevention method to control high sediment concentration turbidity currents. In the present study, some experiments about turbidity current flowing over an obstacle were carried out. Experiments were performed with different obstacle heights, hydraulic conditions and horizontal and steep bed slopes. Results showed that generally the concentration of turbidity current decreases from upstream to downstream of the flume in cases without obstacle. Installing an obstacle generally increased dilution and most of the sediment particles can be retained on upstream side of the obstacle. Based on experimental data, it may be concluded that obstacles with reasonable heights dilute turbidity currents effectively. Trap efficiency reduces by increasing the densimetric Froude Number. Also effect of obstacle in the horizontal slope is more intense than the steep slope. The experimental data of the presented research could be useful for dam and reservoir designers to control and reduce the probability of sedimentation hazards.

\section{Notation}

$V=$ velocity of turbidity current flow

$h=$ inflow turbidity current thickness

$h_{m}=$ height of obstacle

$v=$ kinematics viscosity of flow

$C_{1}=$ concentration of turbidity flow before obstacle

$C_{2}=$ concentration of turbidity flow after obstacle 
$\rho^{\prime}=$ density of turbidity flow

$\rho=$ density of clear water

$\Delta \rho\left(=\rho^{\prime}-\rho\right)=$ difference between turbidity current and fresh water density

$g=$ acceleration due to gravity

$g^{\prime}\left(=\left[\rho^{\prime}-\rho\right] \times g / \rho\right)=$ reduced gravity of current

$S=$ bed slope

$T_{e}\left(=1-C_{2} / C_{1}\right)=$ trap efficiency of obstacle

$\operatorname{Re}(=V h / v)=$ Reynolds Number of turbidity flow

$F r_{d}\left(=V / \sqrt{ } g^{\prime} h\right)=$ densimetric Froude Number

$H_{m}\left(=h_{m} / h\right)=$ dimensionless obstacle height

$D_{50}=$ mean diameter of particle

$G_{s}=$ specific gravity of particle

$Q=$ discharge of turbidity current flow

$L=$ total flume length

$X=$ distance from entrance gate

$C_{0}=$ initial turbidity current concentration

$C=$ concentration in each point of the flume

$U_{f u}=$ front velocity of the turbidity current upstream of the obstacle

$U_{f d}=$ the velocity of outgoing continuing turbidity current downstream of obstacle

\section{References}

Alexander J and Morris S 1994 Observations on experimental, non-channelized, high-concentration turbidity currents and variations in deposits around obstacles. J. Sediment Res. 64(4): 899-909

Asghari Pari S A, Kashefipour S M, Ghomeshi M and Shafaie Bajestan M 2010 Effects of obstacle heights on controlling turbidity currents with different concentrations and discharges. J. Food Agriculture Environment 8(2): 930-935

Bursik M I and Woods A 2000 The effect of topography on sedimentation from particle-laden turbulent density currents. J. Sedimentary Res. 70(1): 53-63

De Cesare G, Schleiss A and Hermann F 2001 Impact of turbidity currents on reservoir sedimentation. ASCE J. Hydraulic Eng. 127(1): 6-16

Fan J and Morris G 1992 Reservoir sedimentation. II: Reservoir desiltation and long term storage capacity. ASCE J. Hydraulic Eng. 118(3): 370-384

Lane-Serff G F, Beal L M and Hadfield T D 1995 Gravity current flow over obstacles. J. Fluid Mech. 292: $39-53$

Morris G L and Fan J 1998 Reservoir sedimentation handbook. Design and management of dams, reservoirs and watersheds for sustainable use. New York: McGraw-Hil

Oehy C H and Schleiss A 2007 Control of turbidity currents in reservoirs by solid and permeable obstacles. ASCE J. Hydraulic Eng. 133(6): 637-648

Oehy C H, De Cesare G and Schleiss A 2010 Effect of inclined jet screen on turbidity current. J. Hydraulic Res. 48(1): 81-90

Prinos P 1999 Two-dimensional density currents over obstacles. Proceeding of $28^{\text {th }}$ IAHR Congress, Graz, Austria, Theme D

Rottman J W, Simpson J E, Hunt J C R and Britter R E 1985 Unsteady gravity current flows over obstacle: Some observations and analysis related to phase II trials. J. Hazardous Mater. 11: 325-340

Woods A W, Bursik M I and Kurbatov A V 1998 The interaction of ash flows with ridges. Bull. Volcanol. 60: $38-51$

Yu W S, Lee H Y and Hsu S H M 2000 Experiments on deposition behavior of fine sediment in a reservoir. ASCE J. Hydraulic Eng. 126(12): 912-920 